\title{
Novas espécies de Esthlogena s. str. Thomson (Coleoptera, Cerambycidae, Lamiinae)
}

\author{
Maria Helena M. Galileo ${ }^{1,3}$ \& Ubirajara R. Martins ${ }^{2,3}$
}

\begin{abstract}
'Museu de Ciências Naturais, Fundação Zoobotânica do Rio Grande do Sul. Caixa Postal 1188, 90001-970 Porto Alegre-RS, Brasil. galileo@fzb.rs.gov.br ${ }^{2}$ Museu de Zoologia, Universidade de São Paulo. Caixa Postal 42494, 04218-970 São Paulo-SP, Brasil. urmsouza@usp.br ${ }^{3}$ Pesquisador do CNPq.
\end{abstract}

\begin{abstract}
New species of Esthlogena s. str. Thomson (Coleoptera, Cerambycidae, Lamiinae). New species described of Pteropliini: Esthlogena (E.) nigrosuturalis from Mexico and Panama; E. (E.) chicacaoensis and E. (E.) amaliae from Guatemala; E. (E.) dissimilis from Peru. All species are illustrated.
\end{abstract}

KEYWORDS. Central America; Mexico; Peru, taxonomy.

RESUMO. Novas espécies de Esthlogena s. str. Thomson (Coleoptera, Cerambycidae, Lamiinae). Novas espécies de Pteropliini descritas: Esthlogena (E.) nigrosuturalis do México e Panamá; E. (E.) chicacaoensis e E. (E.) amaliae da Guatemala; E. (E.) dissimilis do Peru. Todas as espécies são ilustradas.

PALAVRAS-CHAVE. América Central; México, Peru; taxonomia.

O gênero Esthlogena foi proposto por Thomson (1864) para Hebestola comata Thomson, 1857. Contribuições posteriores, (Thomson 1868; Bates 1872, 1880, 1885; Breuning 1940a, 1940b, 1942, 1954, 1969; Aurivillius 1920 e Fisher 1942) acrescentaram ao gênero outras 16 espécies. Breuning (1940b) dividiu o gênero em dois subgêneros, Esthlogena s. str. e Pseudotaxia Breuning, 1940, com base na pontuação elitral: pontos desordenados (Esthlogena) ou pontos alinhados (Pseudotaxia). O gênero foi revisto por Breuning (1961). A distribuição geográfica de Esthlogena estende-se do México, mais ao norte, ao Uruguai, mais meridional (Monné \& Bezark 2009), inclusive uma espécie na América Central insular (Jamaica). Acrescentam-se ao gênero, quatro espécies novas.

$\mathrm{O}$ material estudado pertence às seguintes coleções: American Coleoptera Museum, San Antonio, Texas (ACMS); Museu de Zoologia, Universidade de São Paulo, São Paulo (MZSP).

\section{Esthlogena (E.) nigrosuturalis sp. nov.}

(Figs. 1, 2)

Etimologia. Latim, niger $=$ preto, suturalis = sutura; adjetivo alusivo à sutura dos élitros preta.

Tegumento em geral castanho-avermelhado; tegumento castanho-escuro a preto: nos élitros, em faixas estreitas, uma restrita aos lados do escutelo, outra ao longo da sutura e no centro do metasterno e dos urosternitos. Cabeça revestida por pubescência densa, amarelada; pontuação fina, esparsa e parcialmente acobertada pela pubescência; pontos alinhados junto à orla dos olhos. Região entre os tubérculos anteníferos deprimida. Lobos oculares superiores com cinco fileiras de omatídios, tão distantes entre si quanto o quádruplo da largura de um lobo. Lobos oculares inferiores tão longos quanto às genas. Antenas unicolores revestidas por pubescência amarelada; base dos flagelômeros com anel de pubescência acinzentada. Nos machos, as antenas ultrapassam o ápice elitral na ponta do antenômero VIII e, nas fêmeas, no meio do antenômero XI.

Protórax revestido por pubescência amarelada; com espinho lateral manifesto com comprimento subigual ao do pedicelo. Pubescência do pronoto disposta transversalmente dos lados para o centro; na junção, na metade anterior do pronoto, volta-se para a margem anterior e, na metade basal, dirige-se para a margem posterior; centro do terço posterior do pronoto com pilosidade amarelo-acinzentada. Disco pronotal com pontos finos, esparsos, parcialmente acobertados pela pubescência. Escutelo com pubescência inaparente (macho) ou amarelo-acinzentada (fêmea).

Élitros revestidos por pubescência amarelada, densa; região sutural anterior com pontos grossos, justapostos e não acobertados pela pubescência; lados da sutura com pontos equidistantes nos três quartos apicais; dorso elitral com pontos pequenos, gradualmente mais finos, esparsos, para a margem. No parátipo macho (Fig. 2), pontuação densa atrás dos úmeros no terço basal. Extremidades elitrais obliquamente truncadas.

Face ventral do corpo com pubescência amarelada, densa, mais esparsa no centro do metasterno e dos urosternitos. Lados dos esternitos com pontos pequenos, esparsos, parcialmente acobertados pela pubescência amarelada densa. Pernas com pubescência amarelada, densa. Fêmures com pontos contrastantes, mais evidentes nas fêmeas. Tíbias dos machos, pouco engrossadas. 
Dimensões em mm, macho/fêmea respectivamente. Comprimento total, 12,2/16,1; comprimento do protórax, 2,4/2,8; maior largura do protórax, 3,4/3,9; comprimento elitral, 9,0/ 11,8; largura umeral 3,7/4,4.

Material-tipo. Holótipo fêmea, PANAMÁ. Chiriqui: Cerro Punta, 13.V.1981, J. E. Wappes col. (ACMS). Parátipo macho, MÉXICO, Colima: (vizinhança de El Terrero, 5100 pés), 18.VII.1981, J. E. Wappes col. (MZSP).

Discussão. Esthlogena (E.) nigrosuturalis sp. nov. inserese no grupo de espécies com pubescência amarelada nos esternos torácicos. Assemelha-se a E.(E.) guatemalana Bates, 1885 pelos pro- e mesosterno inteiramente revestidos por pubescência amarelada, densa. Distingue-se pela faixa castanho-escura a preta nos élitros, nos lados do escutelo e ao longo da sutura; pelo espinho lateral do protórax mais curto que o comprimento do pedicelo e pelos pontos elitrais desiguais (maiores, próximo da sutura e menores, gradativamente mais afastados, em direção às margens). Em E. (E.) guatemalana, o tegumento dos élitros é castanho-avermelhado, uniforme; o espinho lateral do protórax é manifesto e mais longo que o comprimento do pedicelo; os pontos elitrais contrastantes são maiores e próximos junto à sutura e menores e irregularmente distribuídos em direção ao ápice.

\section{Esthlogena (E.) chicacaoensis sp. nov.}

(Fig. 3)

Etimologia. O nome é um adjetivo e refere-se ao local de coleta.

Tegumento castanho-escuro, gradativamente mais avermelhado na metade apical dos élitros. Fronte e vértice com pubescência amarelada, densa, intercalada por pontos grossos. Genas com pubescência acinzentada, esparsa. Lobos oculares superiores com seis fileiras de omatídios; distância entre lobos igual ao triplo da largura de um lobo. Lobos oculares inferiores com 1,5 vezes o comprimento das genas. Antenas ultrapassam o ápice elitral no meio do antenômero VIII. Antenômeros castanho-escuros revestidos por pubescência amarelo-esbranquiçada, mais acinzentada na base; com franja de pelos esparsos na margem interna nos antenômeros III e IV.

Protórax com espinho lateral manifesto, mais longo que o pedicelo. Lados do protórax e pronoto revestidos por pubescência amarelada, intercalada por pontos glabros, grossos, mais concentrados nos lados adiante e atrás do tubérculo lateral e mais esparsos e menores no disco pronotal. Mesepimeros, mesepisternos, metepimeros, metepisternos e lados do metasterno com pubescência amarelada densa e pontos esparsos e contrastantes. Prosterno, mesosterno, centro do metasterno e escutelo com pubescência acinzentada esparsa.

Élitros com pubescência amarelo-acinzentada e pontos grandes, contrastantes, mais concentrados na base. Ápice elitral obliquamente truncado.

Pernas revestidas por pubescência acinzentada; fêmures e tíbias com pontos glabros, contrastantes. Urosternitos com pubescência acinzentada; nos lados, com pontos glabros e esparsos.
Dimensões em mm. Comprimento total, 16,6; comprimento do protórax, 3,0; maior largura do protórax, 3,9; comprimento elitral, 12,2; largura umeral, 4,7.

Material-tipo. Holótipo macho, GUATEMALA, Suchitepéquez: Chicacao (10 km NE, 5000 pés), 3.IX.1965, J. M. Campbell col. (ACMS).

Discussão. Esthlogena (E.) chicacaoensis sp. nov. pela face ventral com pubescência amarelada, densa nos lados dos esternos torácicos e pelos urosternitos com pubescência acinzentada, assemelha-se a Esthlogena (E.) guatemalana Bates, 1885. Difere pelo tegumento castanho-escuro, mais avermelhado na metade apical dos élitros e pela pubescência acinzentada no prosterno. Em Esthlogena (E.) guatemalana o tegumento corporal é castanho-avermelhado e o prosterno é revestido por pubescência amarelada.

Esthlogena (E.) chicacaoensis sp. nov. difere de E. (E.) porosa Bates, 1872 pela pilosidade do metasterno amarelada; antenas dos machos com franja de pelos esparsos na margem interna nos antenômeros III e IV; ápice dos élitros obliquamente truncados e pontos elitrais maiores. Em $E$. (E.) porosa a pubescência nos lados do metasterno é acinzentada; as antenas nos machos apresentam franja de pelos moderadamente densa nos antenômeros III a XI; os ápices dos élitros são transversalmente truncados e os pontos elitrais são menores e mais esparsos.

\section{Esthlogena (E.) amaliae sp. nov.}

(Fig. 4)

Etimologia. O nome específico é uma homenagem a Amália Severo Barboza, Museu de Ciências Naturais, Fundação Zoobotânica do Rio Grande do Sul pelos incansáveis préstimos.

Tegumento castanho-escuro, levemente avermelhado no terço apical dos élitros. Cabeça com pubescência amarelada na fronte e no vértice e acinzentada nas genas; pontuação grossa, esparsa. Lobos oculares superiores com seis fileiras de omatídios, tão distantes entre si quanto o triplo da largura de um lobo. Lobos oculares inferiores um terço mais longos que as genas. Antenas ultrapassam o ápice elitral no meio do antenômero X (macho) e no terço apical do XI (fêmea); antenômeros castanho-escuros com pubescência cinza-amarelada com anel basal cinza-esbranquiçado.

Protórax com espinho lateral subigual ao comprimento do pedicelo; coberto por pubescência amarelada, densa, mais acinzentada no espinho lateral. Disco pronotal com pontos grossos, esparsos; na metade basal, intercalados por pontos mais finos.

Élitros com pubescência amarelada e pontos grossos, contrastantes, esparsos; na declividade basal, pontos justapostos. Ápice elitral obliquamente truncado, projetado no ângulo marginal.

Pernas revestidas por pubescência acinzentada; fêmures e tíbias com pontos glabros, contrastantes. Mesepimeros, mesepisternos, metepimeros, metepisternos e lados do 


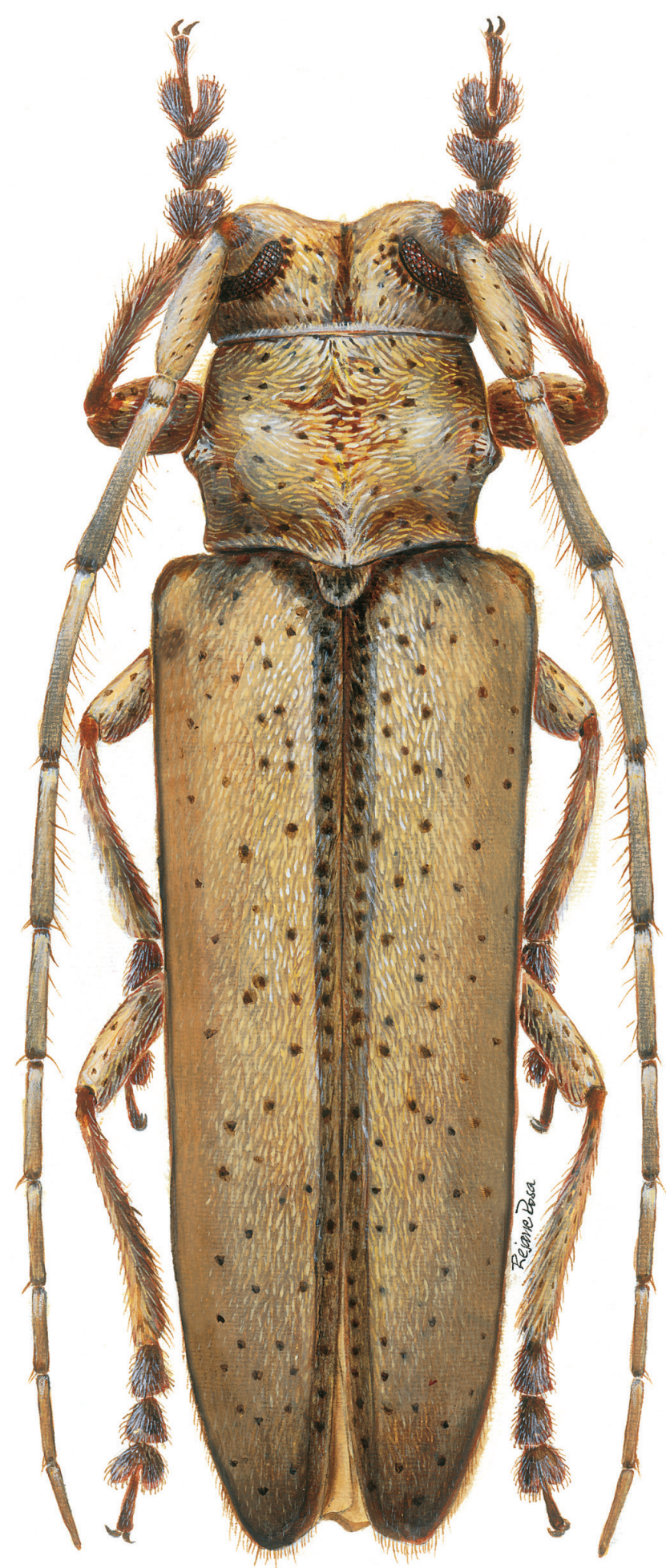

Fig. 1. 1, Esthlogena (E.) nigrosuturalis sp. nov., holótipo fêmea, comprimento $16,1 \mathrm{~mm}$.

metasterno com pubescência amarelada densa e pontos contrastantes, grossos e esparsos. Prosterno, mesosterno, centro do metasterno e escutelo com pubescência acinzentada. Urosternitos com pubescência acinzentada e pontos glabros, esparsos, nos lados.
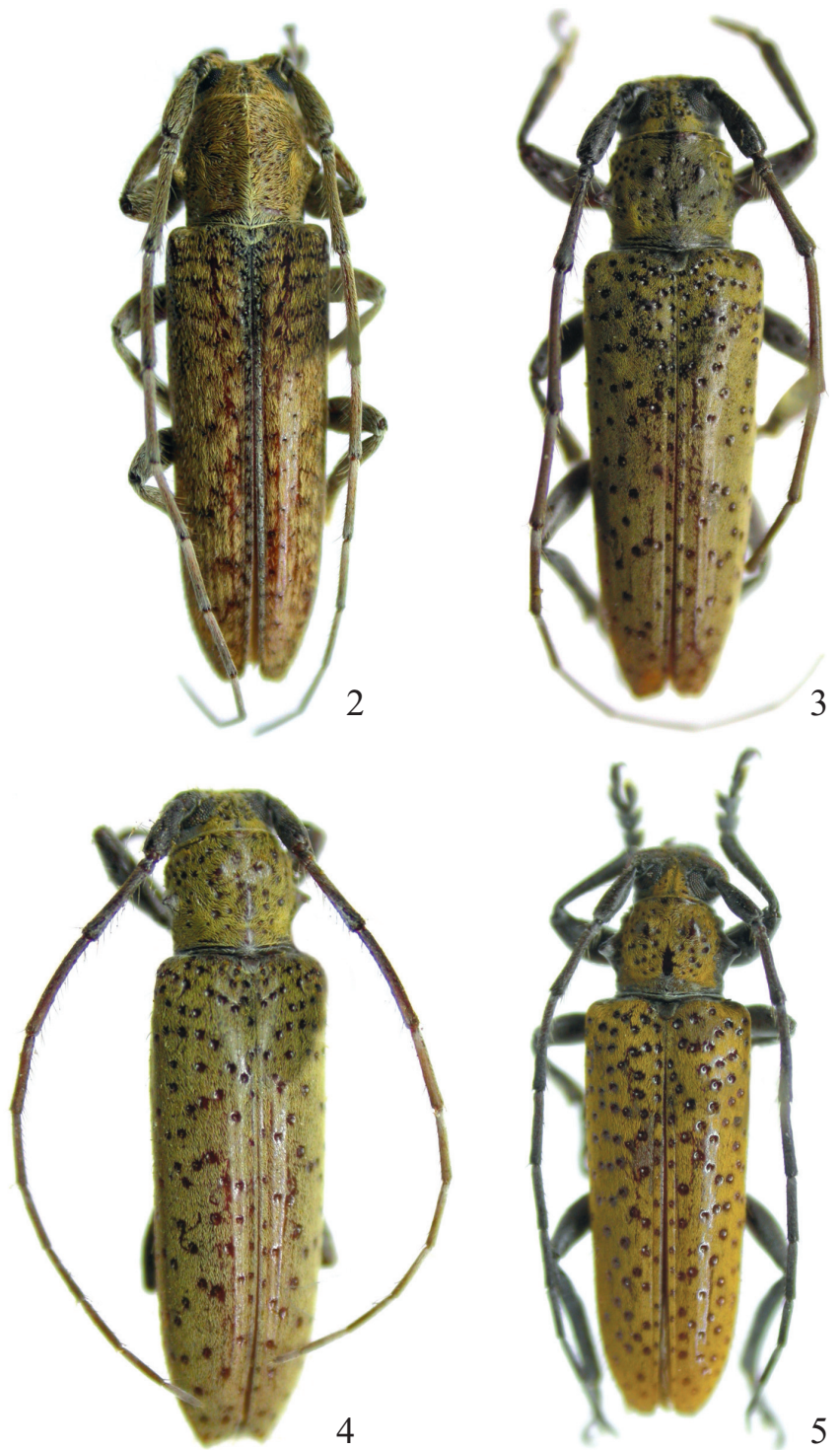

Figs. 2-5. 1, Esthlogena (E.) nigrosuturalis sp. nov., parátipo macho, comprimento 12,2 mm; 3, Esthlogena (E.) chicacaoensis sp. nov., holótipo macho, comprimento $16,6 \mathrm{~mm}$; , Esthlogena (E.) amaliae sp. nov., holótipo macho, comprimento $10,2 \mathrm{~mm}$; 5, Esthlogena (E.) dissimilis sp. nov., holótipo macho, comprimento $12,8 \mathrm{~mm}$.

Dimensões em mm, macho/fêmea respectivamente. Comprimento total, 10,2/12,7; comprimento do protórax, 1,9/2,2; maior largura do protórax, 2,5/3,0; comprimento elitral, 7,6/ 9,7; largura umeral, 2,9/3,5.

Material-tipo. Holótipo macho, GUATEMALA, Suchitepéquez: Cuyotenango (Olimpo, Finca San Rafael, 1700 pés), 28.IV.1996, J. M. Campbell col. (ACMS). Parátipo fêmea, Solola: Santiago Atitlan (5 km S, $1500 \mathrm{~m}), 20$.VIII.1965, J. M. Campbell col. (MZSP).

Discussão. Em E. (E.) amaliae sp. nov. e $E$. (E.) chicacaoensis, o prosterno e o mesosterno têm pubescência acinzentada. E. (E.) amaliae difere de E. (E.) chicacaoensis pela distância entre os lobos oculares superiores igual ao dobro da largura de um lobo; antenas (macho) ultrapassam o 
ápice elitral no meio do $\mathrm{X}$; protórax com espinho lateral subigual ao comprimento do pedicelo e extremidades elitrais obliquamente truncadas e projetadas no ângulo marginal. Em E. (E.) chicacaoensis, a distância entre os lobos oculares superiores é igual ao triplo da largura de um lobo; as antenas do macho ultrapassam o ápice elitral no terço apical do VII; o espinho lateral do protórax é mais longo que o pedicelo e os ápices elitrais são obliquamente truncados.

\section{Esthlogena (E.) dissimilis sp. nov.}

(Fig. 5)

Etimologia. Latim, dissimilis = diferente; adjetivo alusivo aos dois padrões de pubescência.

Tegumento corporal castanho-escuro a preto, exceto disco pronotal e élitros castanho-avermelhados. Cabeça com mancha de pubescência amarelada no vértice. Fronte com pontos grossos concentrados na região entre os tubérculos anteníferos. Lobos oculares superiores com cinco fileiras de omatídios, tão distantes entre si quanto a largura de um lobo aproximadamente. Lobos oculares inferiores com o triplo do comprimento das genas. Antenas alcançam o ápice elitral na extremidade do antenômero X; unicolores com pubescência fina, acinzentada.

Lados do protórax com espinho central manifesto e gibosidade projetada, próxima da margem anterior. Pronoto com pubescência densa, amarelada; lados do pronoto e faixa junto à margem posterior, com pubescência acinzentada; no centro essa faixa alarga-se levemente e a pubescência cinza é intercalada pela amarelada. Disco pronotal com pontos grossos e esparsos, dispostos a cada lado do centro. Escutelo revestido por pubescência acinzentada.

Élitros cobertos por pubescência densa, amarelada, intercalada por pontos grandes e contrastantes da base ao ápice; no terço basal, pontos profundos e próximos; gradativamente mais rasos e esparsos no restante da superfície. Ápices elitrais subarredondados.

Face ventral revestida por pubescência fina, acinzentada. Lados do metasterno e urosternitos com alguns pontos finos, esparsos. Tíbias dos machos engrossadas.

Dimensões em mm. Comprimento total, 12,8; comprimento do protórax, 2,2; maior largura do protórax, 3,2; comprimento elitral, 9,7; largura umeral, 3,8.

Material-tipo. Holótipo macho, PERU, Cusco: MachuPicchu (Torentoy Canion, base de Machu-Picchu, $2000-$ 2200 m), VI-VII.1964, B. Malkin col. (MZSP).

Discussão. Esthlogena (E.) dissimilis sp. nov. assemelha-se a $E$. (E.) foveolata Aurivillius, 1920 por possuir a face ventral inteiramente revestida por pubescência acinzentada e as antenas unicolores com pubescência uniforme, mas difere principalmente pelo ápice elitral subarredondado e pelo terço basal dos élitros com pontos mais próximos entre si (Fig. 5). Em E. (E.) foveolata, o ápice elitral é projetado em espinho no ângulo marginal e a pontuação na base dos élitros é mais uniforme com os pontos mais separados.

Esthlogena (E.) dissimilis difere de E. (E.) porosa, descrita da Nicarágua, pelos lados do protórax com espinho lateral manifesto e gibosidade próxima à margem anterior projetada e pela pontuação grossa do pronoto e dos élitros. Em E. (E.) porosa, os lados do protórax possuem apenas espinho central, curto e o pronoto e os élitros apresentam pontuação fina e esparsa.

\section{AGRADECIMENTOS}

A James E. Wappes (ACMS) pelo envio de material para estudo; a Rejane Rosa, desenhista do Museu de Ciências Naturais, Fundação Zoobotânica do Rio Grande do Sul (MCNZ), pela ilustração a cores; a Eleandro Moysés (Bolsista IC/CNPq/ MCNZ), pela execução das fotografias e digitalização das imagens; a Amália S. Barboza (Bolsista AT/CNPq/MCNZ) pela contribuição na curadoria da coleção de Cerambycidae; a Erica H. Buckup (MCNZ) pela leitura crítica.

\section{REFERÊNCIAS}

Aurivillius, C. 1920. Neue oder wenig bekannte Coleoptera Longicornia. 17. Arkiv för Zoologi 13: 361-403.

Bates, H. W. 1872. On the longicorn Coleoptera of Chontales, Nicaragua. Transactions of the Entomological Society of London 1872: 163238.

Bates, H. W. 1880. Biologia Centrali-Americana. Insecta, Coleoptera, Longicornes. v. 5, 17-152.

Bates, H. W. 1885. Biologia Centrali-Americana. Insecta, Coleoptera, suppl. to Longicornia, London. v. 5, 249-436.

Breuning, S. 1940a. Novae species Cerambycidarum. VIII. Folia Zoologica et Hydrobiologica 10: 37-85.

Breuning, S. 1940b. Novae species Cerambycidarum. IX. Folia Zoologica et Hydrobiologica 10: 115-214

Breuning, S. 1942. Novae species Cerambycidarum. XI. Folia Zoologica et Hydrobiologica 11: 113-175.

Breuning, S. 1954. Nouvelles formes de Lamiaires (Septiéme partie). Bulletin de le Institute Royale des Sciences Naturelles de Belgique 30: $1-24$.

Breuning, S. 1961. Revision des Pteropliini. Pesquisas (5) 9: 5-60.

Breuning, S. 1969. Nouveaux coléoptères Cerambycidae Lamiinae des collections du Muséum de Paris. Bulletin du Muséum d'Histoire Naturelle (2) 41: 187-199.

Fisher, W. S. 1942. New West Indian cerambycid beetles III. Torreia 10: 143.

Monné, M. A. \& L. G. Bezark. 2009. Checklist of the Cerambycidae, or longhorned wood-boring beetles, of the Western Hemisphere. Rancho Dominguez (CA), BioQuip Publications, 455 p.

Thomson, J. 1864. Systema cerambycidarum ou exposé de tous les genres compris dans la famille des cérambycides et familles limitrophes. Mémoires de la Société Royale des Sciences de Liège 19: 1-352.

Thomson, J. 1868. Matériaux pour servir a une révision des Desmiphorites. Physis Recueil d'Histoire Naturelle 2: 101-146. 